\title{
Awareness About Covid-19 and Post Covid Complications Among Dental Practitioners in Bangalore - An Interventional Questionnaire Study
}

\author{
Gaurav $^{3 *}$,Bhagya Balakrishnan ${ }^{1}$, Vathsala Naik², Amandeep Sodhi ${ }^{4}$, \\ Sangeetha $^{5}$ and Aghina Pradeep ${ }^{6}$ \\ ${ }^{1} I^{\text {nd }}$ Year Postgraduate Student, Bangalore Institute of Dental Sciences and Hospital \\ and Postgraduate Research Centre, Bangalore, Karnataka, India \\ ${ }^{2}$ Head of the Department, Department of Oral Medicine and Maxillofacial Radiology, \\ Bangalore Institute of Dental Sciences and Hospital and Postgraduate Research \\ Centre, Bangalore, Karnataka, India \\ ${ }^{3}$ Assistant Professor, Department of Oral Medicine and Maxillofacial Radiology, \\ Bangalore Institute of Dental Sciences and Hospital and Postgraduate Research \\ Centre, Bangalore, Karnataka, India \\ ${ }^{4}$ Department of Oral Medicine and Maxillofacial Radiology, Bangalore Institute of Dental \\ Sciences and Hospital and Postgraduate Research Centre, Bangalore, Karnataka, India \\ ${ }^{5}$ Reader, Department of Oral Medicine and Maxillofacial Radiology, Bangalore Institute \\ of Dental Sciences and Hospital and Postgraduate Research Centre, Bangalore, \\ Karnataka, India \\ ${ }^{6}$ Final Year Postgraduate, Bangalore Institute of Dental Sciences and Hospital and \\ Postgraduate Research Centre, Bangalore, Karnataka, India \\ *Corresponding Author: Gaurav, Assistant Professor, Department of Oral Medicine \\ and Maxillofacial Radiology, Bangalore Institute of Dental Sciences and Hospital and \\ Postgraduate Research Centre, Bangalore, Karnataka, India.
}

\author{
Received: October 21, 2021 \\ Published: November 30, 2021 \\ (C) All rights are reserved by Gaurav., et al.
}

\footnotetext{
Abstract

Background: Coronavirus (COVID-19) has caused a significant impact on the human life. The COVID-19 virus is predominantly known to affect the ACE2 receptors present on vital organs like lungs, kidney, liver and Intestine. But most affected is the respiratory system. Although the incubation period is from 1-14 days, 3-7 days are the most critical phase in the infectious period. Some of the most common presenting features of COVID-19 include dry cough, fever, dyspnoea, myalgia, joint pain, fatigue, gastrointestinal symptoms, and loss of taste and smell. Post-coronavirus disease/(COVID-19) syndrome includes persistence of symptoms even after the viral clearance and exaggeration of chronic diseases within a month. Various alterations in the immunity of the body, accounts for numerous life-threatening conditions viz, deep fungal infections, deep vein thrombosis, etc. Mucormycoses is one of the most seen maladies among them. Hence for oral physicians identifying these post covid oral manifestations and treating them aptly becomes an acute need of the hour to prevent mortality in Covid 19 patients. The available data regarding the short and long-term consequences of COVID-19 is still insufficient and the awareness about it among dental practitioners appears questionable. Hence an interventional questionnaire study was planned to assess post covid awareness.

Aim: To assess the awareness amongst dentists in Bangalore about COVID-19 and post Covid complications.
}

Citation: Gaurav., et al. "Awareness About Covid-19 and Post Covid Complications Among Dental Practitioners in Bangalore - An Interventional Questionnaire Study". Acta Scientific Dental Sciences 5.12 (2021): 119-129. 
Research Question: Do the dental professionals in Bangalore have adequate awareness about post covid complications?.

Methodology: The study participants consisted of dental professionals working in Bangalore who weren't associated with academics. This study used a self-administered validated questionnaire consisting of 25 questions. A key for the questions were prepared and given to the subjects after the initial questionnaire assessment. After 2 weeks of initial questionnaire assessment the dental practioners were again given the same questionnaire and reassessed for awareness once again and the data was analysed.

Result and Conclusion: Based on the questionnaire study, the pre and post awareness was assessed. It was found that among varied questions, the dental practitioners ranging from 50-70\% were well informed about pre and post covid complications. Further an answer key for all the 25 questions were given to the dental practitioners. With this, statistics showed a progression of $90-100 \%$ awareness.

Keywords: Covid-19; Post Covid Complications; Mucormycoses; ACE-2; Cytokine Storm

\section{Introduction}

In 2020, the world suffered the most catastrophic experience of the century due to coronavirus disease 2019 (COVID-19) caused by SARS-CoV-2 virus. COVID-19 was broadcasted as a public health emergency on January 30, 2020 and was subsequently declared a pandemic on March 11, 2020 by the WHO. The most common clinical features of COVID-19 include dry cough, fever, dyspnoea, myalgia, joint pain, fatigue, gastrointestinal symptoms and loss of smell and taste. Although the lungs are the first target organ of COVID-19 infection, the virus may also exhibit infections in different organs including the heart, liver, kidneys, gut, and brain as ACE-2 receptors are found on these organs also.

Patients who recover from COVID-19 can have persistent symptoms such as fatigue, dyspnoea, dry coughing, congestion or shortness of breath, loss of taste or smell, loss of hearing, body aches, diarrhoea, nausea, chest or abdominal pain. Other complications include acute kidney injury with little evidence of renal failure and hepatic impairment in severely ill patients. Moreover, there have been evidence of abnormalities in the clotting system, such as disseminated intravascular coagulopathy (DIC), decreased platelet count, and prolonged prothrombin time (PT) along with hypercoagulability and potential thromboembolic disorders.

Hence post covid disease awareness among health professionals, and in particular dental professionals is a must. It becomes a social responsibility to educate and assess this awareness so that patients could be helped. With this in mind an interventional study was planned to assess this among dental professionals.
Aim

To assess the awareness amongst dentists in Bangalore about covid-19 and post Covid complications.

Research question

The dental professionals in Bangalore, do they have adequate awareness about covid-19 and post covid complications?.

\section{Materials and Methods}

This study used a self-administered questionnaire consisting of 25 questions which had undergone proper validation. The questionnaire was given in a set of 2 by which the pre awareness and post awareness of the dental practitioners were assessed after having educated the dental practitioners with the answer key for the second set. The second set of same questionnaires was given 15 days after giving the answer key.

Questionnaire for assessing the awareness of covid-19 and post covid complications among dental professionals

DATE:

Details of Dentist

Name

Age

Gender

Professional qualification

Years of experience 
1. Covid 19 has declared as a pandemic by WHO in
a. Jan $31^{\text {st }} 2020$
b. April $25^{\text {th }} 2020$
c. March $11^{\text {th }} 2020$
d. May $1^{\text {st }} 2020$
e. Don't know

2. Time required by virus to make intracellular virions after which cytopathic effects occurs and infections spread to other cells is called as-
a. Window period
b. Eclipse period
c. Latent period
d. Recalcitrant period
e. Don't know

3. S - protein on SARS COV -2 virus surface gets locked to which key on cell surface alveolus?
a. ACE 2
b. ACE 1
c. Ribosomes
d. Golgi apparatus
e. Don't know

4. Eclipse period of SARS COVID-19 is:
a. $10 \mathrm{hrs}$
b. $9 \mathrm{hrs}$
c. $24 \mathrm{hrs}$
d. $48 \mathrm{hrs}$
e. Don't know

5. Incubation period of covid 19 virus is
a. 1 to 6 days
b. 2 to 14 days
c. 12 to 24 days
d. 20 to 30 days
e. Don't know

6.Protein on SARS Cov 2 virus surface is-
a. $\mathrm{S}$
b. $\mathrm{P}$
c. D
d. B
e. Don't know

7. The main symptoms of Corona are
a) fever $>38^{\circ} \mathrm{C}$
b) cough and sore throat
c) shortness of breath
d) All of the above
e) Don't know

8. $1^{\text {st }}$ sign of overlap between COVID-19 and other respiratory disorders includes-
a. Flu like illness
b. Whooping cough
c. Pneumonia
d. All of the above
e. Don't know

9. Specific method for diagnosis of Sars Cov 2-
a) RT PCR (Real Time Reverse Transcriptase Polymerase Chain Reaction)
b) DNA Polyploidy
c) Both a and b
d) ELISA
e) Don't know

10. Test employed for respiratory specimen in Covid 19 disease is-
a. $\quad$ RT-PCR
b. NAAT (Nucleic Acid Amplification Test)
c. DNA amplification test
d. ELISA
e. Don't know 
11. Complications of COVID-19 include:
a. ARDS
b. Septic shock
c. Multiple organ dysfunction
d. Increased mortality
e. All of the above
f. Don't know

12. What are the prolonged post-COVID-19 symptoms in oral cavity in recovered patients?
a) Fungal infections such as mucormycosis
b) Herpetic stomatitis
c) Ageusia
d) Xerostomia
e) All of the above
f) Don't know

13. Covid pattern on chest X Ray:
a) Bilateral peripheral ground glass opacities
b) Consolidations
c) Cavitations
d) Both a and b
e) Both b and c
f) Don't know

14. Central ground glassing surrounded by peripheral consolidation is called as:
a. Atoll sign
b. Consolidation
c. Crazy paving
d. None of the above
e. Don't know

15. Facts about Co RADS include-
a. Stand for covid 19 Reporting and data system
b. Does not talk about severity index
c. Depicts level of suspicion
d. All of the above.
e. Don't know

16.Liver function abnormalities seen in COVID-19 patients include increase in:
a. AST
b. ALT and HBDH
c. GGT and LDH
d. All of the above
e. Don't know

17. Significance of a positive d dimer test includes:
a. The presence of an abnormally high level of fibrin degrada- tion products.
b. It indicates that there may be significant blood clot (throm- bus) formation and breakdown in the body, but it does not tell the location or cause
c. Both of the above
d. Don't know

18. Drug that can prevent the cytokine release syndrome seen in COVID-19 is:
a) Remdesivir
b) Hydroxychloroquine
c) Ivermectin
d) Tocilizumab
e) Don't know

19. What all medical history should be taken care of during dental treatment of post covid patients
a. Steroids taken
b. Blood sugar levels
c. Vascular co-morbidities
d. Antiplatelet medication
e. All of the above
f. Don't know

20. Characteristic presentations of Mucormycosis include:
a) Abscess and dry ulcers
b) Skin swelling
c) Necrosis
d) Eschars
e) All of the above
f) Don't know 
21. Palatal ulceration seen in the picture below is most commonly seen secondary to which of the following deep fungal infections:

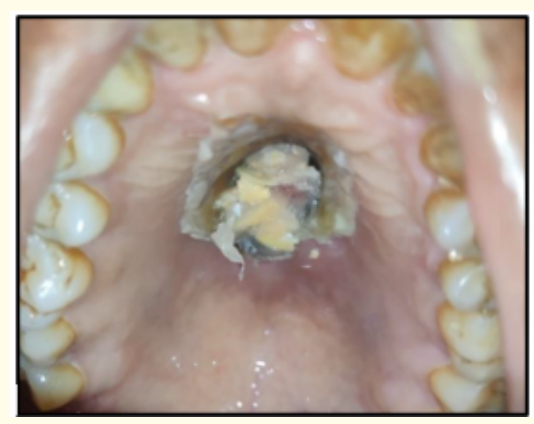

Figure 1
25. Prevention methods for Mucormycosis include:

a) Controlling hyperglycemia

b) Optimal steroid usage

c) Do not consider all Covid 19 cases for immunomodulators

d) Use humidifiers with clean distilled water during oxygen therapy.

e) All of the above

f) Don't know

\begin{tabular}{|c|c|c|c|c|c|}
\hline & N & Minimum & Maximum & Mean & Std. Deviation \\
\hline AGE & 110 & 24 & 66 & 34.81 & 8.556 \\
\hline
\end{tabular}

Table 1: Mean age distribution of the subjects.

The dental professionals who participated in the questionnaire had a minimum age of 24 and a maximum age of 66 .
a) Uncontrolled DM
b) Case of concurrent or recently ( $<6$ weeks) treated severe Covid 19
c) Use of immunosupressants
d) All of the above
e) Don't know

23. First line treatment for Mucormycosis:
a) Amphotericin-B (Lyposomal)
b) Azoles
c) Triazoles
d) All of the above.
e) Don't know

24. Which of these drugs is administered IV in cases of Mucormycosis:
a) Isavuconazole
b) Posaconazole
c) Both a and b
d) Don't know

\begin{tabular}{|l|c|c|}
\hline Gender & Frequency & Percent \\
\hline FEMALES & 63 & 57.3 \\
\hline MALES & 47 & 42.7 \\
\hline Total & 110 & 100.0 \\
\hline
\end{tabular}

Table 2: Distribution of the subjects based on age.

63 of the participants were females and 47 were males.

Some of the questions and their pre and post response are compared in the tables below

\begin{tabular}{|c|c|c|c|c|}
\hline & \multirow{2}{*}{ Responses } & & Post & \multirow{2}{*}{ Total } \\
\hline & & & March $11^{\text {th }}, 2020$ & \\
\hline \multirow[t]{12}{*}{ PRE } & \multirow[t]{2}{*}{ Jan $31^{\text {st }} 2020$} & Count & 14 & 14 \\
\hline & & $\%$ & $100.0 \%$ & $100.0 \%$ \\
\hline & \multirow[t]{2}{*}{ April 25 2020} & Count & 15 & 15 \\
\hline & & $\%$ & $100.0 \%$ & $100.0 \%$ \\
\hline & \multirow{2}{*}{$\begin{array}{c}\text { March } 11^{\text {th }} \\
2020\end{array}$} & Count & 73 & 73 \\
\hline & & $\%$ & $100.0 \%$ & $100.0 \%$ \\
\hline & \multirow[t]{2}{*}{ May $1^{\text {st }}, 2020$} & Count & 1 & 1 \\
\hline & & $\%$ & $100.0 \%$ & $100.0 \%$ \\
\hline & \multirow[t]{2}{*}{ Don't know } & Count & 7 & 7 \\
\hline & & $\%$ & $100.0 \%$ & $100.0 \%$ \\
\hline & \multirow[t]{2}{*}{ Total } & Count & 110 & 110 \\
\hline & & $\%$ & $100.0 \%$ & $100.0 \%$ \\
\hline
\end{tabular}

Table 3: Comparison of the pre and post responses for question 1 - covid 19 has declared as a pandemic by WHO. 
Before the answer key was given $66.3 \%$ of the dental professionals got the right answer and $100 \%$ got it right after the answer key was given.

\begin{tabular}{|c|c|c|c|c|c|}
\hline & \multirow{2}{*}{ Responses } & & \multicolumn{2}{|c|}{ Post } & \multirow{2}{*}{ Total } \\
\hline & & & ACE 2 & ACE 1 & \\
\hline \multirow[t]{12}{*}{ PRE } & \multirow{2}{*}{ ACE 2} & Count & 61 & 1 & 62 \\
\hline & & $\%$ & $98.4 \%$ & $1.6 \%$ & $100.0 \%$ \\
\hline & \multirow{2}{*}{ ACE 1} & Count & 7 & 0 & 7 \\
\hline & & $\%$ & $100.0 \%$ & $0.0 \%$ & $100.0 \%$ \\
\hline & \multirow{2}{*}{ Ribosomes } & Count & 9 & 0 & 9 \\
\hline & & $\%$ & $100.0 \%$ & $0.0 \%$ & $100.0 \%$ \\
\hline & \multirow{2}{*}{$\begin{array}{l}\text { Golgi ap- } \\
\text { paratus }\end{array}$} & Count & 1 & 0 & 1 \\
\hline & & $\%$ & $100.0 \%$ & $0.0 \%$ & $100.0 \%$ \\
\hline & \multirow{2}{*}{ Don't know } & Count & 31 & 0 & 31 \\
\hline & & $\%$ & $100.0 \%$ & $0.0 \%$ & $100.0 \%$ \\
\hline & \multirow{2}{*}{ Total } & Count & 109 & 1 & 110 \\
\hline & & $\%$ & $99.1 \%$ & $.9 \%$ & $100.0 \%$ \\
\hline
\end{tabular}

Table 4: Comparison of the pre and post responses for question 3 - s - protein on SARS COV -2 virus surface gets locked to which key on cell surface alveolus.

About $56.36 \%$ of dental professionals got the answer correct before the answer key was given. Evaluation after the answer key showed that there was an increase of $99.1 \%$ who got it right.

\begin{tabular}{|c|c|c|c|c|}
\hline & \multirow{2}{*}{ Responses } & & POST & \multirow{2}{*}{ Total } \\
\hline & & & All of the above & \\
\hline \multirow[t]{10}{*}{ PRE } & \multirow[t]{2}{*}{ fever $>38 \mathrm{C}$} & Count & 17 & 17 \\
\hline & & $\%$ & $100.0 \%$ & $100.0 \%$ \\
\hline & \multirow{2}{*}{$\begin{array}{l}\text { Cough and } \\
\text { Sore throat }\end{array}$} & Count & 14 & 14 \\
\hline & & $\%$ & $100.0 \%$ & $100.0 \%$ \\
\hline & \multirow{2}{*}{$\begin{array}{l}\text { All of the } \\
\text { above }\end{array}$} & Count & 78 & 78 \\
\hline & & $\%$ & $100.0 \%$ & $100.0 \%$ \\
\hline & \multirow[t]{2}{*}{ Don't know } & Count & 1 & 1 \\
\hline & & $\%$ & $100.0 \%$ & $100.0 \%$ \\
\hline & \multirow[t]{2}{*}{ Total } & Count & 110 & 110 \\
\hline & & $\%$ & $100.0 \%$ & $100.0 \%$ \\
\hline
\end{tabular}

Table 5: Comparison of the pre and post responses for question 7 - The main symptoms of Corona.
Before the answer key was given $70 \%$ of the dental professionals got the right answer and $100 \%$ got it right after the answer key was given.

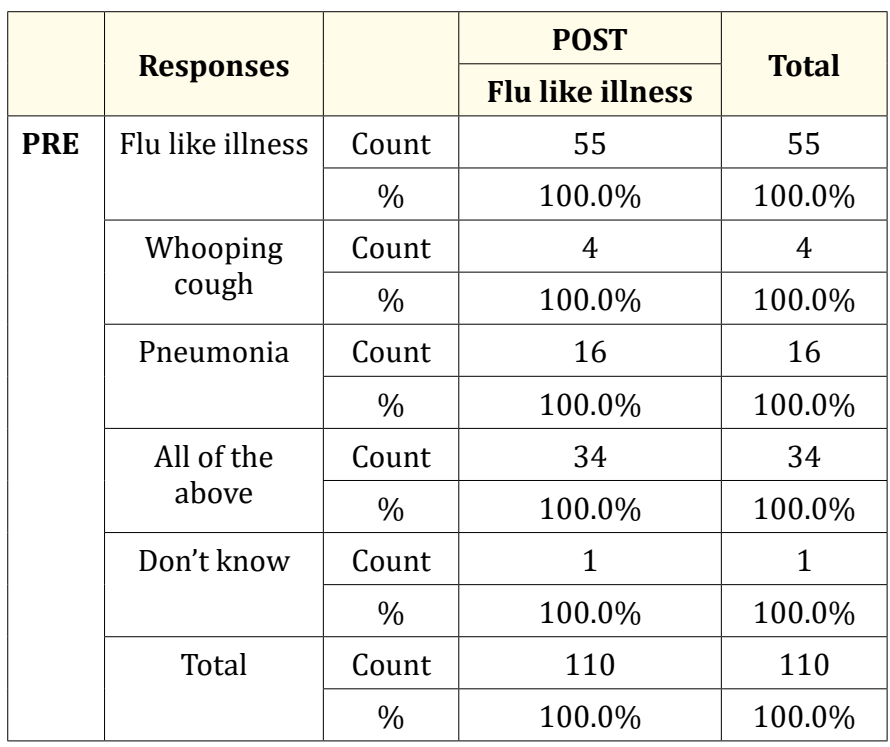

Table 6: Comparison of the pre and post responses for question 8 - $1^{\text {st }}$ sign of overlap between COVID-19 and other respiratory disorders includes.

Before the answer key was given $50 \%$ of the dental professionals got the right answer and $100 \%$ got it right after the answer key was given.

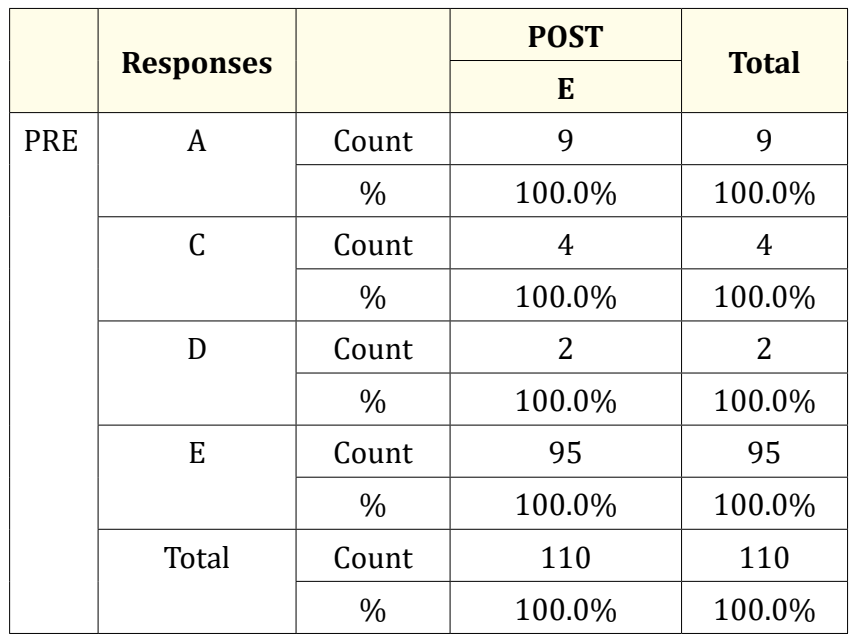

Table 7: Comparison of the pre and post responses for question 11 - Complications of COVID-19 include. 
Before the answer key was given $86.3 \%$ of the dental professionals got the right answer and $100 \%$ got it right after the answer key was given (Table 8).
Before the answer key was given $71.8 \%$ of the dental professionals got the right answer and $100 \%$ got it right after the answer key was given (Table 9).

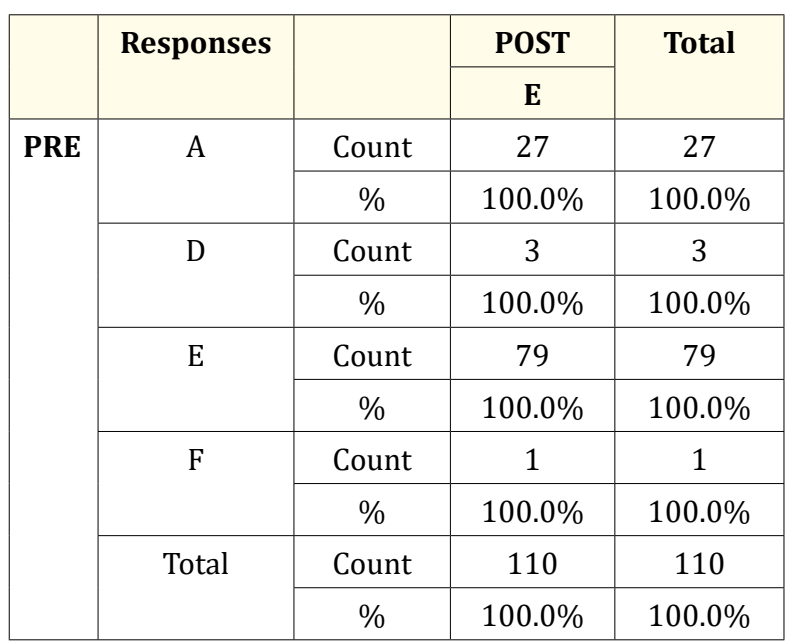

Table 8: Comparison of the pre and post responses for question 12 - What are the prolonged post-COVID-19 symptoms in oral cavity in recovered patients?.

\begin{tabular}{|c|c|c|c|c|c|c|}
\hline & \multirow{2}{*}{ Responses } & & \multicolumn{3}{|c|}{ POST } & \multirow{2}{*}{ Total } \\
\hline & & & $\mathbf{b}$ & c & d & \\
\hline \multirow[t]{14}{*}{ PRE } & \multirow{2}{*}{$\begin{array}{l}\text { Bilateral peripheral } \\
\text { ground glass opacities }\end{array}$} & Count & 0 & 0 & 10 & 10 \\
\hline & & $\%$ & $0.0 \%$ & $0.0 \%$ & $100.0 \%$ & $100.0 \%$ \\
\hline & \multirow[t]{2}{*}{ Consolidations } & Count & 1 & 1 & 7 & 9 \\
\hline & & $\%$ & $11.11 \%$ & $11.11 \%$ & $77.77 \%$ & $100.0 \%$ \\
\hline & \multirow[t]{2}{*}{ Cavitation's } & Count & 0 & 0 & 11 & 11 \\
\hline & & $\%$ & $0.0 \%$ & $0.0 \%$ & $100.0 \%$ & $100.0 \%$ \\
\hline & \multirow[t]{2}{*}{ Both $a$ and $b$} & Count & 0 & 0 & 71 & 71 \\
\hline & & $\%$ & $0.0 \%$ & $0.0 \%$ & $100 \%$ & $100.0 \%$ \\
\hline & \multirow[t]{2}{*}{ Both $b$ and $c$} & Count & 0 & 1 & 4 & 5 \\
\hline & & $\%$ & $0.0 \%$ & $20.0 \%$ & $80.0 \%$ & $100.0 \%$ \\
\hline & \multirow[t]{2}{*}{ Don't know } & Count & 0 & 0 & 4 & 4 \\
\hline & & $\%$ & $0.0 \%$ & $0.0 \%$ & $100.0 \%$ & $100.0 \%$ \\
\hline & \multirow[t]{2}{*}{ Total } & Count & 1 & 2 & 107 & 110 \\
\hline & & $\%$ & $9.1 \%$ & $3.6 \%$ & $97.27 \%$ & $100.0 \%$ \\
\hline
\end{tabular}

Table 9: Comparison of the pre and post responses for question 13 - Covid pattern on chest X Ray.

Before the answer key was given $64.5 \%$ of the dental professionals got the right answer and $97.27 \%$ got it right after the answer key was given (Table 10).
Before the answer key was given $54.54 \%$ of the dental professionals got the right answer and $82.72 \%$ got it right after the answer key was given (Table 11). 


\begin{tabular}{|c|c|c|c|c|c|c|c|}
\hline & \multirow{2}{*}{ Responses } & & \multicolumn{4}{|c|}{ POST } & \multirow{2}{*}{ Total } \\
\hline & & & $\mathbf{a}$ & b & c & d & \\
\hline \multirow[t]{12}{*}{ PRE } & \multirow[t]{2}{*}{$\mathrm{a}$} & Count & 0 & 8 & 7 & 0 & 15 \\
\hline & & $\%$ & $0.0 \%$ & $53.33 \%$ & $46.67 \%$ & $0.0 \%$ & $100.0 \%$ \\
\hline & \multirow[t]{2}{*}{ b } & Count & 0 & 0 & 0 & 10 & 10 \\
\hline & & $\%$ & $0.0 \%$ & $0.0 \%$ & $0.0 \%$ & $100.0 \%$ & $100.0 \%$ \\
\hline & \multirow[t]{2}{*}{$c$} & Count & 1 & 0 & 2 & 3 & 6 \\
\hline & & $\%$ & $16.7 \%$ & $0.0 \%$ & $33.3 \%$ & $50.0 \%$ & $100.0 \%$ \\
\hline & \multirow[t]{2}{*}{ d } & Count & 0 & 0 & 0 & 60 & 60 \\
\hline & & $\%$ & $0.0 \%$ & $0.0 \%$ & $0.0 \%$ & $100 \%$ & $100.0 \%$ \\
\hline & \multirow[t]{2}{*}{ e } & Count & 1 & 0 & 0 & 18 & 19 \\
\hline & & $\%$ & $5.26 \%$ & $0.0 \%$ & $0.0 \%$ & $94.73 \%$ & $100.0 \%$ \\
\hline & \multirow[t]{2}{*}{ Total } & Count & 2 & 8 & 9 & 91 & 110 \\
\hline & & $\%$ & $1.81 \%$ & $7.27 \%$ & $8.1 \%$ & $82.72 \%$ & $100.0 \%$ \\
\hline
\end{tabular}

Table 10: Comparison of the pre and post responses for question 18 - Drug that can prevent the cytokine release syndrome seen in COVID-19.

\begin{tabular}{|c|c|c|c|c|}
\hline & \multirow{2}{*}{ Responses } & & POST & \multirow{2}{*}{ Total } \\
\hline & & & $\mathbf{e}$ & \\
\hline \multirow[t]{10}{*}{ PRE } & \multirow[t]{2}{*}{ A } & Count & 5 & 5 \\
\hline & & $\%$ & $100.0 \%$ & $100.0 \%$ \\
\hline & \multirow[t]{2}{*}{ D } & Count & 2 & 2 \\
\hline & & $\%$ & $100.0 \%$ & $100.0 \%$ \\
\hline & \multirow[t]{2}{*}{$\mathrm{E}$} & Count & 102 & 102 \\
\hline & & $\%$ & $100.0 \%$ & $100.0 \%$ \\
\hline & \multirow[t]{2}{*}{$\mathrm{F}$} & Count & 1 & 1 \\
\hline & & $\%$ & $100.0 \%$ & $100.0 \%$ \\
\hline & \multirow[t]{2}{*}{ Total } & Count & 110 & 110 \\
\hline & & $\%$ & $100.0 \%$ & $100.0 \%$ \\
\hline
\end{tabular}

Table 11: Comparison of the pre and post responses for question 19 - What all medical history should be taken care of during dental treatment of post covid patients.

Before the answer key was given $66.3 \%$ of the dental professionals got the right answer and $100 \%$ got it right after the answer key was given (Table 12).

Before the answer key was given $81 \%$ of the dental professionals got the right answer and $100 \%$ got it right after the answer key was given (Table 13).

\begin{tabular}{|c|c|c|c|c|}
\hline & \multirow{2}{*}{ Responses } & & POST & \multirow{2}{*}{ Total } \\
\hline & & & $\mathbf{e}$ & \\
\hline \multirow[t]{12}{*}{ PRE } & \multirow[t]{2}{*}{$\mathrm{a}$} & Count & 2 & 2 \\
\hline & & $\%$ & $100.0 \%$ & $100.0 \%$ \\
\hline & \multirow[t]{2}{*}{ c } & Count & 13 & 13 \\
\hline & & $\%$ & $100.0 \%$ & $100.0 \%$ \\
\hline & \multirow[t]{2}{*}{ d } & Count & 1 & 1 \\
\hline & & $\%$ & $100.0 \%$ & $100.0 \%$ \\
\hline & \multirow[t]{2}{*}{ e } & Count & 90 & 90 \\
\hline & & $\%$ & $100.0 \%$ & $100.0 \%$ \\
\hline & \multirow[t]{2}{*}{$\mathrm{f}$} & Count & 4 & 4 \\
\hline & & $\%$ & $100.0 \%$ & $100.0 \%$ \\
\hline & \multirow[t]{2}{*}{ Total } & Count & 110 & 110 \\
\hline & & $\%$ & $100.0 \%$ & $100.0 \%$ \\
\hline
\end{tabular}

Table 12: Comparison of the pre and post responses for question 20 - Characteristic presentations of Mucormycosis include.

Before the answer key was given $64.5 \%$ of the dental professionals got the right answer and $100 \%$ got it right after the answer key was given (Table 14).

Before the answer key was given $70 \%$ of the dental professionals got the right answer and $100 \%$ got it right after the answer key was given in Graph 1. 


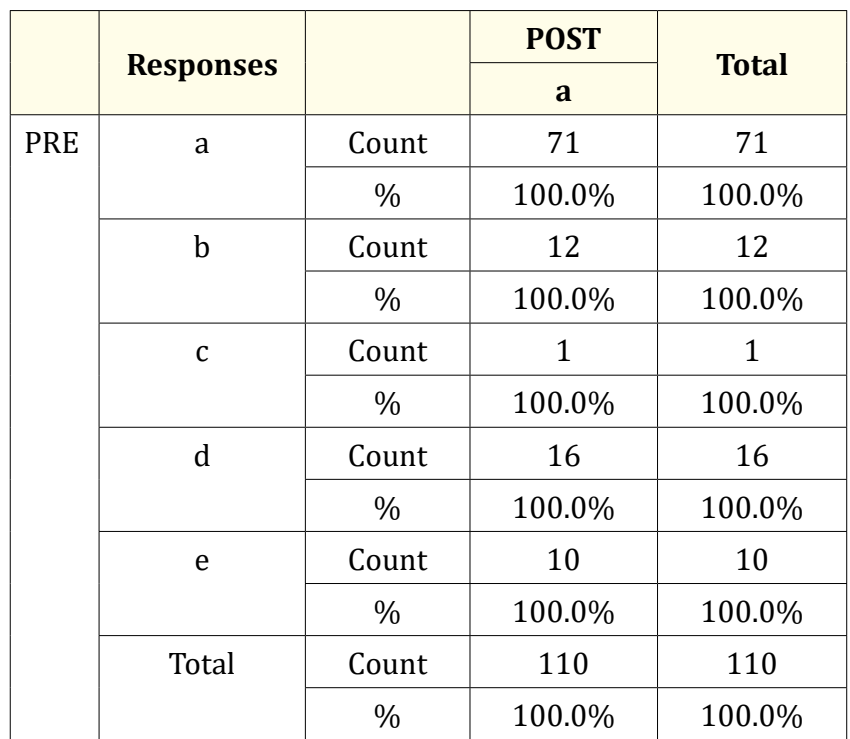

Table 13: Comparison of the pre and post responses for question 23 - First line treatment for Mucormycosis.

\begin{tabular}{|c|c|c|c|c|}
\hline & \multirow{2}{*}{ Responses } & & POST & \multirow{2}{*}{ Total } \\
\hline & & & d & \\
\hline \multirow[t]{14}{*}{ PRE } & \multirow[t]{2}{*}{ a } & Count & 7 & 7 \\
\hline & & $\%$ & $100.0 \%$ & $100.0 \%$ \\
\hline & \multirow[t]{2}{*}{$\mathrm{b}$} & Count & 11 & 11 \\
\hline & & $\%$ & $100.0 \%$ & $100.0 \%$ \\
\hline & \multirow[t]{2}{*}{$\mathrm{c}$} & Count & 6 & 6 \\
\hline & & $\%$ & $100.0 \%$ & $100.0 \%$ \\
\hline & \multirow[t]{2}{*}{ d } & Count & 7 & 7 \\
\hline & & $\%$ & $100.0 \%$ & $100.0 \%$ \\
\hline & \multirow[t]{2}{*}{ e } & Count & 77 & 77 \\
\hline & & $\%$ & $100.0 \%$ & $100.0 \%$ \\
\hline & \multirow[t]{2}{*}{$\mathrm{f}$} & Count & 2 & 2 \\
\hline & & $\%$ & $100.0 \%$ & $100.0 \%$ \\
\hline & \multirow[t]{2}{*}{ Total } & Count & 110 & 110 \\
\hline & & $\%$ & $100.0 \%$ & $100.0 \%$ \\
\hline
\end{tabular}

Table 14: Comparison of the pre and post responses for question 25 - Prevention methods for Mucormycosis include.

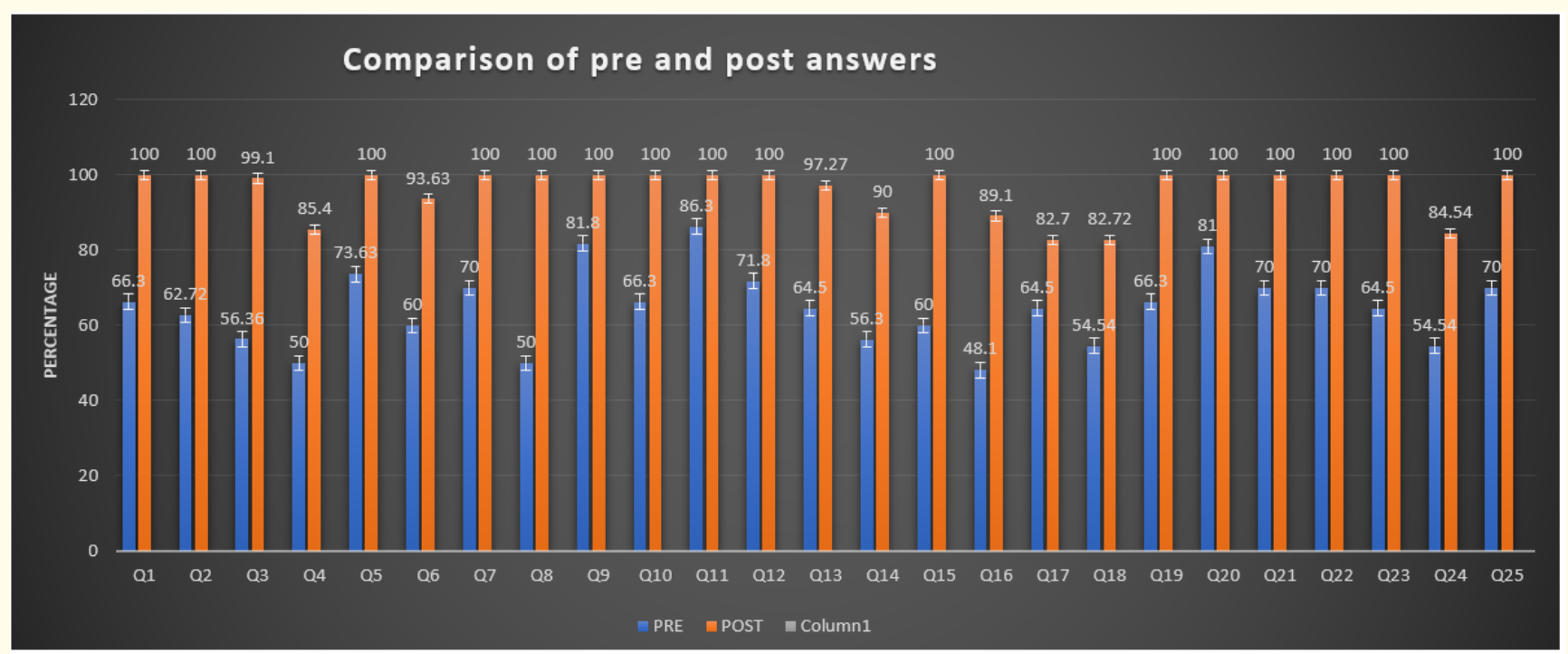

Graph 1: Comparison of pre and post awareness responses.

\section{Results}

Based on the questionnaire study, the pre and post awareness was assessed. It was found that among varied questions, the dental practitioners ranging from $50-70 \%$ were well informed about pre and post covid complications. Further an answer key for all the 25 questions were given to the dental practitioners. With this, statistics showed a progression of $85-100 \%$ awareness. With this, our research question was answered and accomplished. 


\section{Discussion}

\section{Structure}

Coronaviruses are enveloped spherical particles with a size of 150 to $160 \mathrm{~nm}$. SARS (severe acute respiratory syndrome)-CoV virus is a positive single stranded RNA, with viral proteins namely nucleocapsid protein( $\mathrm{N})$, membrane glycoprotein $(\mathrm{M})$, envelope protein (E) and spike glycoprotein (S). COVID-19 virus i.e. SARSCoV2 virus differs from other corona viruses by encoding an additional glycoprotein named acetyl esterase and haemagglutination (HE). COVID-19 primarily targeted the lungs by acting on ACE-2 receptors and caused alveolar contraction by altering the surface tension and exchange of gases. ACE- 2 receptors are also found on liver, kidney, intestine etc.

\section{Pathophysiology}

The spike protein of SARS-CoV-2 virus binds to the ACE-2 receptors, which are mostly seen in adult nasal epithelial cells and enters the cell by endocytosis. After entering the cell viral RNA is released and translated to proteins which starts to undergo replication to produce more viral Nucleocapsids. The pro inflammatory cytokines and inflammatory markers such as interleukins (IL-1, IL6 , IL-8, IL-120 and IL-12), tumour necrosis factor- $\alpha$ (TNF- $\alpha$ ), IFN- $\lambda$ and IFN- $\beta$, CXCL- 10 , monocyte chemoattractant protein-1 (MCP-1) and macrophage inflammatory protein $-1 \alpha(\mathrm{MIP}-1 \alpha)^{1}$ are released. This 'cytokine storm' acts as a chemoattractant for neutrophils, CD4 helper T cells and CD8 cytotoxic T cells and begins to get sequestered in the lung tissue. This results in diffuse alveolar damage which eventually culminates in an acute respiratory distress syndrome. ACE-2 receptors are also found on several organs like kidney, liver, intestine etc on which SARS-CoV-2 virus acts resulting in multiple organ diseases.

\section{Symptoms}

Some of the most common presenting features of COVID-19 include dry cough, fever, dyspnoea, myalgia, joint pain, fatigue, gastrointestinal symptoms, and loss of taste and smell. Some of the oral manifestations are rashes in the mouth, oral ulcers, angular cheilitis, bad breath, dry mouth, loss of taste etc.

\section{Investigations}

\section{Molecular tests (RT-PCR)}

\section{Blood tests [1]}

- A normal or decreased white blood cell count (and lymphopenia) is observed in many cases.
- Increased levels of lactate dehydrogenase, $\mathrm{C}$ reactive protein, creatine kinase (CK MB and CK MM), aspartate aminotransferase and alanine amino-transferase can be seen.

- Increased D-dimer levels and an elevated neutrophil to lymphocyte ratio are seen in some patients.

- Coagulation abnormalities can be observed in severe cases, with an increase in prothrombin time and international normalised ratio.

\section{Chest X-ray}

In the early stages of the disease Chest X-ray might not show any significant changes. As the infection progresses, bilateral multifocal alveolar opacities with consolidations are observed [1].

\section{High-resolution computed tomography (HRCT)}

The most commonly seen features are multifocal bilateral 'ground-glass' areas associated with consolidation. A 'reversed halo sign' also known as Atoll sign is also seen in some patients, which is identified as a focal area of patchy opacities surrounded by a peripheral ring with consolidation. Other findings include pleural effusion, cavitation, calcification, and lymphadenopathy.

\section{POST covid complications}

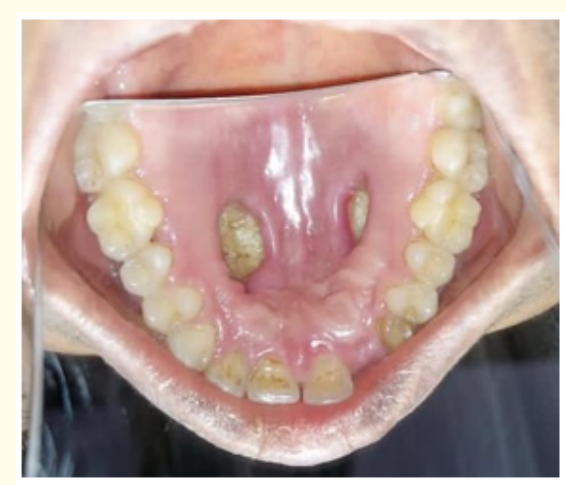

Figure 2

Post covid complications include neurological, pulmonary, mucocutaneous, psychological, cardiovascular and oral manifestations. Some of the pulmonary manifestations are dyspnoea, cough, chest pain etc. Some cardiac complications are palpitations, myocarditis, pericarditis and heart failure. Other complications include acute kidney injury and hepatic impairment in severely ill patients. Psychiatric manifestations like depression, post-traumatic stress disorder, anxiety etc are noticed. Cutaneous symptoms like ery- 
thematous rash, urticarial rash and persistent COVID toes are seen in some cases. Fatigue, myalgia, joint pain, peripheral neuropathy and peripheral limb ischemia are also found in many post covid patients. Abnormalities in the clotting system, such as disseminated intravascular coagulopathy (DIC), decreased platelet count, and prolonged prothrombin time (PT) are been recorded in several cases along with hypercoagulability and potential thromboembolic disorders. Brain fog is one of the most common neurological manifestation. Encephalopathy and stroke are also seen in some cases.

\section{Results}

Unawareness about the covid-19 and post covid complications lead to several morbidities and complications. To avoid such complications, we in our department decided to do an interventional questionnaire study to assess the awareness and increase the knowledge of dental professionals about COVID-19 and post covid complications. A questionnaire containing 25 questions were prepared which had undergone proper validation. Questionnaire was given to 110 dental professionals in and around central Bangalore. The assessment of results showed $50-70 \%$ of dental professionals had adequate knowledge about COVID-19 and post covid complications. An answer key was given to the respective dental professionals. After 15 days another set of same questionnaires was given and results were analysed which showed an increase in awareness to $85-100 \%$ [2-7].

\section{Conclusion}

The present study reported a satisfactory knowledge among dentists in the awareness of COVID-19 disease and Post covid complications and was even able to upgrade their knowledge about the same. An early identification and management of post covid complications by the dental team will reduce the risk for oral complications and associated morbidities and comorbidities.

\section{Bibliography}

1. Parasher A. "COVID-19: Current understanding of its pathophysiology, clinical presentation and treatment". Postgraduate Medical Journal 97.1147 (2021): 312-320.

2. Carvalho-Schneider C., et al. "Follow-up of adults with noncritical COVID-19 two months after symptom onset". Clinical Microbiology and Infection 27 (2021): 258-263.
3. Bizzoca ME., et al. "Covid-19 pandemic: What changes for dentists and oral medicine experts? A narrative review and novel approaches to infection containment". International Journal of Environmental Research and Public Health 17.11 (2020): 3793.

4. Aldhuwayhi S., et al. "Covid-19 Knowledge and Perceptions Among Dental Specialists: A Cross-Sectional Online Questionnaire Survey". Risk Management and Healthcare Policy 14 (2021): 2851.

5. Alwazzan RA., et al. "Dental Professional's Knowledge, Preventive Awareness and Attitude Towards COVID-19 in Saudi Arabia: A Cross-Sectional Survey". Risk Management and Healthcare Policy 14 (2021): 2277.

6. Arnold DT., et al. "Patient outcomes after hospitalisation with COVID-19 and implications for follow-up: Results from a prospective UK cohort". Thorax (2020).

7. Mandal S., et al. "Long-COVID': A cross-sectional study of persisting symptoms, biomarker and imaging abnormalities following hospitalisation for COVID-19". Thorax (2020).

\section{Volume 5 Issue 12 December 2021 (C) All rights are reserved by Gaurav., et al.}

